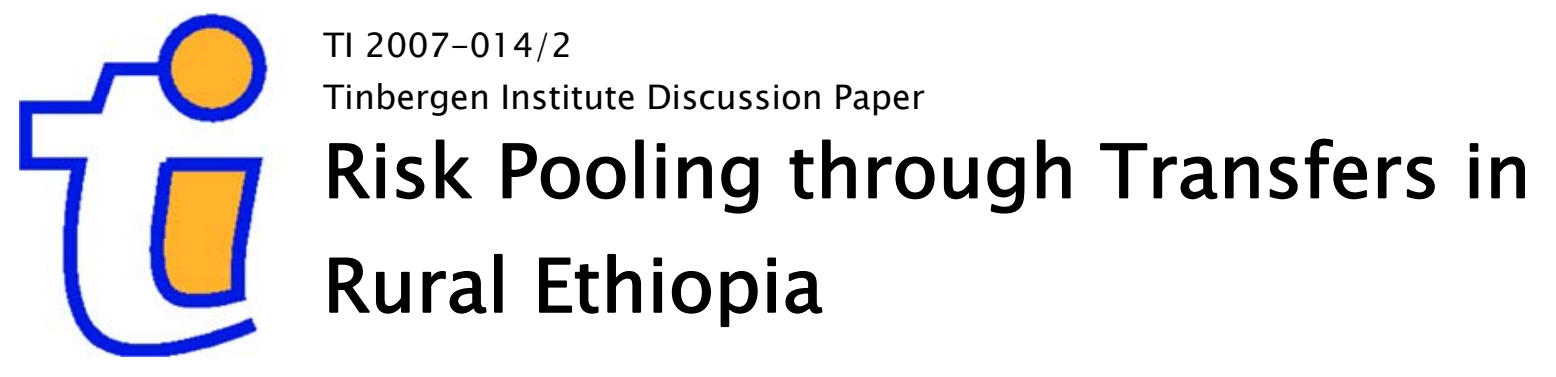

Lei Pan

Vrije Universiteit Amsterdam, and Tinbergen Institute. 


\section{Tinbergen Institute}

The Tinbergen Institute is the institute for economic research of the Erasmus Universiteit Rotterdam, Universiteit van Amsterdam, and Vrije Universiteit Amsterdam.

Tinbergen Institute Amsterdam

Roetersstraat 31

1018 WB Amsterdam

The Netherlands

Tel.: $\quad+31(0) 205513500$

Fax: $\quad+31(0) 205513555$

Tinbergen Institute Rotterdam

Burg. Oudlaan 50

3062 PA Rotterdam

The Netherlands

Tel.: $\quad+31(0) 104088900$

Fax: $\quad+31(0) 104089031$

Most TI discussion papers can be downloaded at http:/ /www.tinbergen.nl. 


\title{
Risk Pooling through Transfers in Rural Ethiopia*
}

\author{
Lei Pan \\ Vrije Universiteit Amsterdam and Tinbergen Institute
}

September 28, 2007

\section{FEWEB-VU}

De Boelelaan 1105

1081 HV Amsterdam

The Netherlands

phone: +31205986145

fax: +31205986004

email: lpan@feweb.vu.nl

${ }^{*}$ The author thanks the Editor and two anonymous referees of the journal Economic Development and Cultural Change, Jan Willem Gunning and Chris Elbers for their very useful comments; Stefan Dercon for providing the aggregated data of income, consumption and livestock and John Cockburn for letting me use his programs for estimating the income function. All errors are my own. 


\begin{abstract}
It is often assumed that transfers received from government, nongovernment organizations (NGOs), friends and relatives help rural households to pool risk. In this paper I investigate two functions of transfers in Ethiopia: risk pooling and income redistribution. Unlike most of the literature this paper investigates not only whether but also how much risk pooling is achieved. I find evidence that transfers from government/NGOs play a role in insuring covariant income shocks and evidence that transfers from both government/NGOs and friends/relatives target the poorer households. However, the contributions of these transfers to risk pooling and income redistribution are economically very limited. Moreover, transfers from friends/relatives do not play a role in risk sharing. Although transfers only play a minor role in risk pooling, households in the study villages are found to be able to insure most of their idiosyncratic income shocks and part of their covariant income shocks.
\end{abstract}




\section{Introduction}

Risk is a major issue in developing countries. Many researchers have stressed the severity of risk in developing countries (Baulch and Hoddinott 2000, Fafchamps 2003 and Dercon 2005a are examples). Kinsey, Burger and Gunning (1998) find that harvest failures were very frequent in the resettlement areas in rural Zimbabwe. Lybbert et al. (2004) claim that among the pastoralists in the arid and semi-arid lands of eastern and southern Africa, livestock losses during one cycle of drought and recovery can be up to $50 \%$ to $80 \%$ for cattle and $30 \%$ for sheep and goats. In the Ethiopia Rural Household Survey (ERHS), farmers were asked to list the shocks they experienced in 1999-2004. 52\% of the households reported drought, $38 \%$ reported pests or diseases affecting crops or livestock and 35\% reported the death of a household member (Dercon, Hoddinott and Woldehanna 2005).

Households employ several methods to cope with these types of risk. Strategies include accumulating and decumulating assets (e.g. Deaton 1991), diversifying agricultural income by planting multiple crops (e.g. Dercon 1996), shifting labor to off-farm employment (e.g. Kochar 1999), or taking loans (e.g. Udry 1990, $1994^{1}$ and Fafchamps and Lund 2003) or transfers (e.g. Dercon and Krishnan 2003).

There are many empirical studies on the issue of risk pooling. Most of them

consider two questions. The first is whether risk is fully insured. The most famous example is Townsend (1994), which tests full insurance by regressing 
individual consumption on individual income and aggregated village consumption or income. This idea that under full insurance idiosyncratic shocks should not have a significant impact on consumption is adopted by many researchers (for example, Grimard 1997, Ravallion and Chaudhuri 1997, Jalan and Ravallion 1999, De Weerdt and Dercon 2006 all applied this idea in their papers).

The second question is how responsive the risk pooling strategies are to shocks. This is usually done by regressing a variable which indicates a measure of risk coping strategy on shocks. For example, Jalan and Ravallion (2001) study the relation between unproductive liquid assets and risk. Fafchamps and Lund (2003) explore how gifts, informal loans, and sales of livestock and grain respond to shocks. Kochar (1999) investigates how households increase their labor supply to cope with risk.

Despite the rich literature in risk pooling, most of the papers can only provide an answer to whether there is full insurance, but not how much the impact of different risk pooling strategies is on risk pooling. It is tempting to use the coefficient from the Townsend test to measure how far away the observed risk sharing is from full insurance. However, such an interpretation should be done with caution as households can rely on self-insurance instead of social insurance to stabilize their consumption. To take an extreme example, in a community where self-insurance through consumption smoothing is the only method for risk management, the Townsend test would suggest a high extent of risk pooling when in fact there is none. This suggests that the Townsend 
coefficient cannot be used as a measure of the extent of risk sharing.

In the studies of specific strategies, usually only the significance of coefficients is meaningful. The value itself does not tell how much risk is insured by a certain strategy since the variables of shocks are usually dummies or indices (examples using the ERHS dataset are Dercon 2004 and Dercon et al. 2005).

It is not always enough to only know if a certain strategy plays a role in risk pooling. Estimating how much shocks are pooled is essential for researchers to evaluate the importance of different strategies. For example, one worry about introducing formal insurance to farmers in developing countries is that it will crowd out informal insurance, which can be a big loss for the households. If informal insurance does play a role in insuring risk, whether or not to implement formal insurance depends on how much the impact of informal insurance is on risk pooling. Therefore, going from a qualitative measure of the degree of risk sharing to a quantitative measure is a crucial step in understanding the risk pooling behavior of households.

In this paper I focus on risk pooling through transfers using ERHS data. To help poor households in bad times government and non-government organizations (NGOs) provide food aid and food-for-work programs. A large amount of food aid is distributed every year in Ethiopia. The annual volume of cereal food aid has ranged between $3.5 \%$ and $26 \%$ of the total domestic food grain production over the 1985-96 period (Clay, Molla and Habtewold 1999). However, the targeting of food aid is poor: Dercon and Krishnan 
(2003) report that the characteristics of those who obtained aid and those who did not differ very little. While there are many studies on informal social networks, the studies on public transfers are rather few. This paper will pay attention to this topic.

Aside from external aid from government and NGOs, mutual support is also very common in rural Ethiopia. Hoddinott, Dercon and Krishnan (2005) study the networks in ERHS villages and find that many households have connections to different sorts of social networks and get support from them. In good years, households send transfers to households suffering negative shocks; in bad years, they receive support from other households. From this point of view, transfers work like an insurance which collects premiums from households with positive shocks and compensates the households with negative shocks.

The social networks in which such risk pooling occurs can be informal, based on kinship, friendship or religion. These social networks may not be designed to pool risk (Fafchamps and Gubert 2005 provide an example for rural Philippines). There are also semi-formal organizations in rural Ethiopia. These organizations require membership and fees, and provide support to their members in bad times. For example, the funeral association iddir is prevalent in Ethiopia. The institution collects contributions from its members and pays out to a household when a member or relative of a member dies (Hoddinott et al. 2005). 
In this paper I explore two functions of transfers. It is well known that shocks can have persistent effects on growth (for example, Dercon 2004 provides evidence of this for Ethiopia). Transfers may play a role in insuring shocks. The degree of risk pooling through transfers depends on the type of shocks. If the shocks are idiosyncratic, households may be able to rely on their social networks to insure the shocks. If the shocks are covariant, households will not be able to do so since the social networks are usually geographically concentrated. This is likely to be the case in the surveyed villages, where Hoddinott et al. (2005) find that $87 \%$ of the individuals in the households' social networks are in the same village. Therefore, it is unlikely that households are able to rely on their social networks to insure covariant income shocks and government actions are necessary for households to avoid the welfare loss from covariant income shocks. Therefore, two measures of shocks are constructed in this paper: covariant income shocks and idiosyncratic income shocks. By decomposing the shocks in this way, I study the roles that transfers from government or NGOs and friends or relatives play in insuring these two types of shocks separately.

However, households with negative shocks are not necessarily poor households. Transfers may try to target not only the unlucky households but also the poorer households. Transfers are then used to reallocate income from richer households to poorer households. In this case, transfers do not depend on shocks but on income differentials. In this paper, I investigate the role of net transfers and inflows of transfers in risk pooling and income redistribution. 
In summary, this paper makes two contributions. First, while many researchers have studied the risk pooling strategies, most can only answer whether risk is fully insured. In this paper I use continuous rather than discrete measures of shocks which are constructed from a regression of income on income determinants. How much risk pooling households achieve through transfers can be studied based on the shocks I construct. Second, this paper explores not only transfers from informal social networks but also transfers from government and NGOs, on which studies are rather few.

This paper is organized as follows. Section 2 describes the dataset. Section 3 gives the econometric specification. Section 4 discusses the results. Section 5 concludes the paper.

\section{Data}

The data used in this paper are from the Ethiopia Rural Household Survey (ERHS). The survey data are collected by the Economics Department of Addis Ababa University in collaboration with the Center for the Study of African Economies at Oxford University and the International Food Policy Research Institute and is one of the few panel data sets available at the household level in Africa. In 1989, around 450 households in six sites were initially surveyed for a famine study. Three more sites were added in 19941995 to include areas north of Debre Birhan, which could not be surveyed 
in 1989 due to military conflict. Six other sites were also added to cover the main agroclimatic zones and farming systems of the richer parts of the country ${ }^{2}$.

In total 1477 households were surveyed in the beginning of 1994. In constructing the panel, the sample was stratified to include a sufficient coverage of the main farming systems and to ensure that female and landless households were included. These households have been re-interviewed several times subsequently. New survey rounds took place in the second half of 1994, in 1995, 1997, 1999 and 2004. The data from the first five of the seven rounds are publicly available. Since the 1989 survey uses a very different questionnaire from the later rounds and also covered different villages, I only use the data from the 1994 (two rounds), 1995 and 1997 surveys in this paper.

The data set provides detailed information on household income and assets as well as transfers. Means and standard deviations of household income and assets can be found in Table 1. The income data are collected by asking about four sources of household income: farm income, labor income, livestock income and transfer income.

Land is allocated by Peasant Associations ${ }^{3}$ in Ethiopia. Selling land is illegal though renting and share-cropping exist ${ }^{4}$. Livestock are the most important productive assets for the households in the surveyed villages. The other productive assets like hoes and plows are only $7 \%$ of the livestock in value ${ }^{5}$. 
As the survey was designed in 1989 for studying the drought in 1984-1985, questions about shocks were asked in each round of the survey. For example, information about rainfall and shocks on crops is provided by the data. The data also contain information about changes in household composition, and birth and death of livestock. However, since the questions are mainly in the form of yes and no, the data do not contain much quantitative information of risk. Thus in this paper I measure risk based on observed income.

The ERHS data provide information about households' transfer income from which the amount of transfers each household receives can be identified. The income data include not only food aid but also other income from transfers. The data indicate whether the transfer is from friends and relatives ${ }^{6}$ or from government and NGOs, and how much each household earns from food-forwork programs.

The transfers households hand out are part of their expenditures. Taxes and contributions to peasant associations are treated as the transfers to government/NGOs. Transfers to friends and relatives include several types of transfers: food the household gives out, educational and medical expenses the household pays for members of other households, contributions to church and iddir, and contributions for livestock loss (Erteban).

The surveys 94a, 95 and 97 were conducted in similar seasons. In the first round (94a) and fourth round (97) surveys, information of transfers including all those given and received in the four months before the surveys was 
collected. For comparison purposes, the data in the 1995 survey are adjusted if the time between the 94b survey and the 95 survey is not four months.

The descriptive statistics for transfers are given in Table 2. There are three characteristics of the transfers that should be noted from Table 2. First, we can see from the big differences between the 99th percentiles and the maxima that there are a few observations with very high levels of transfers. These observations with very high levels of transfers are very likely to reflect measurement errors. For example, the units of the in-kind transfers were recorded incorrectly in the survey.

Second, the amount of "food given out" is large compared to other transfers. Since only the amount of food given out one week before each survey was asked, the data have to be multiplied by a large number (17.3) to make it a four-month total. Thus I consider these data to be noisy and exclude them from the later analyses.

Third, transfer levels are generally low. Because of the outliers, the medians are probably better measures of the level than the means. Compared to the income level in Table 1, transfers amount to less than 15 percent of income (obtained by multiplying transfers by 3 to adjust the 4 month total to a yearly total).

Of course the impact of transfers on insuring income risk depends not only on average transfer levels but also on their distributions. In Table 3, I list 
the medians of income, the value of transfers given out and received and the percentage of households which give out or receive transfers in each village in each year. It is clear from the table that a high percentage of households hand out transfers, but transfers received is location-dependent, for both transfers from government and NGOs and friends and relatives. Comparing the medians of income to the percentages of households which receive and hand out transfers in villages, I find some cases which may reflect income redistribution. For example, in the rich village Sirbana Godeti almost all the households transfer out, while in the relatively poor village Shumsha a high percentage of the households receive transfers from government/NGOs ${ }^{7}$. Some cases which may reflect insurance can also be found. For example, the income in Geblen in 97 is much lower because of a drought than that in the other two years, so $63 \%$ of the households in the village get transfers from government/NGOs. However, Table 3 also shows that not all the poor vil-

lages and villages which are suffering from negative shocks are reached by transfers.

\section{The effects of transfers, risk pooling and redistribution}

\subsection{The income equation and measures of shocks}

In this section, I construct two kinds of shocks: covariant income shocks and idiosyncratic income shocks. Several methods have been used in the 
literature to measure income shocks. Rosenzweig (1988) uses the difference between a household's income and its mean income over a nine-year panel. Jacoby and Skoufias (1997) define the idiosyncratic shock as the deviation of the change in log full income from the change in the village-season-year mean and the aggregate shock as the mean change itself. Kochar (1999) measures income shocks as the residual in a regression of crop profits on a household fixed effect, lagged income and the amount of land owned. Similar to Kochar (1999), I define my income shocks as the difference between household income $y_{t}$ (excluding transfers) at period $t$ and the household's expected income $E_{t-1} y_{t}$ (excluding transfers) at period $t-1$ as determined from a regression of $y_{t}$ on a set of income determinants. I assume that income depends on three components: capital, labor and land. In the ERHS context, capital takes the form of livestock. Demographic variables and other household characteristics are used as additional predictors. As mentioned in section 2, the data contain some information about income related shocks so they are also included in the regressors. Using a constant elasticity of substitution (CES) as the functional form of the income function ${ }^{8}$, household income is modeled as

$$
\begin{aligned}
y_{v h t}= & \left(\alpha_{1} k_{v h t-1}^{-\rho}+\alpha_{2} l a b_{v h t-1}^{-\rho}+\alpha_{3} l a n_{v h t-1}^{-\rho}\right)^{-\frac{\tau}{\rho}} \\
& \exp \left(\sum_{i} \eta_{i} a_{i, v h t-1}+\sum_{j} \phi_{j} c_{j, v h}+\sum_{t} \varpi_{t} l_{t}+\sum_{p} \lambda_{p} w_{p, v h t}\right. \\
& \left.+\sum_{q} \chi_{q} o_{q, v h t}+\text { cons }+e_{v h t}\right) \\
l a b_{v h t-1}= & m_{v h t-1}+\beta_{1} f_{v h t-1}+\beta_{2} c h_{v h t-1}
\end{aligned}
$$


where $v, h, t$ are indexes of village, household, time respectively and $\alpha_{i}, \beta_{i}$, $\eta_{i}, \phi_{j}, \varpi, \lambda_{p}$ and $\chi_{q}$ are coefficients. The parameter $\tau$ is the scale return of production and $\rho$ is the substitution parameter. The variable $y$ is household income excluding transfers, $k$ is livestock, $l a b$ is the aggregate household labor as defined in equation (2), and lan is land. The variables $m, f$ and $c h$ are the male, female and children in the household respectively ${ }^{9}$. The variables $a_{i}$ and $c_{j}$ denote time-variant and time-invariant predictors, respectively ${ }^{10}$. The definitions of these variables are listed in Table 1. Village dummies are included in the variables $c_{j}$ to capture the village fixed effect. The variable $l_{t}$ denotes the year dummies. The variable $w_{p}$ denotes observed weather related shocks and $o_{q}$ denotes the other observed shocks. Table 4 lists the definitions of $w_{p}$ and $o_{q}$. Weather related shocks are the shocks caused by rain, temperature, storm and flood. Other shocks are shocks on crops caused by diseases, livestock, birds, and shocks on livestock and the composition of households. The variable cons is a constant and $e$ is the error term.

It should be noted that in the income function defined in (1) and (2) the error term $e_{v h t}$ is correlated across households. Since village dummies and year dummies are included in $c_{j}$ and $l_{t}, e_{v h t}$ can be written as

$$
e_{v h t}=g_{v t}+b_{v h}+n_{v h t}
$$

where $g_{v t}, b_{v h}$ and $n_{v h t}$ denote the unobserved village specific shocks, the household effect ${ }^{11}$ and the unobserved idiosyncratic shocks respectively and $g_{v t} \sim N\left(0, \sigma_{g}^{2}\right), b_{v h} \sim N\left(0, \sigma_{b}^{2}\right), n_{v h t} \sim N\left(0, \sigma_{n}^{2}\right)$. 
I also allow for serial correlation in the shocks:

$$
\begin{aligned}
& \operatorname{cov}\left(e_{v h, 94}, e_{v h, 95}\right)=c_{1}^{g} \sigma_{g}^{2}+\sigma_{b}^{2}+c_{1}^{n} \sigma_{n}^{2}=\sigma_{1}^{2}, \\
& \operatorname{cov}\left(e_{v h, 95}, e_{v h, 97}\right)=c_{2}^{g} \sigma_{g}^{2}+\sigma_{b}^{2}+c_{2}^{n} \sigma_{n}^{2}=\sigma_{2}^{2}, \\
& \operatorname{cov}\left(e_{v h, 94}, e_{v h, 97}\right)=c_{3}^{g} \sigma_{g}^{2}+\sigma_{b}^{2}+c_{3}^{n} \sigma_{n}^{2}=\sigma_{3}^{2} .
\end{aligned}
$$

where $c_{1}^{g}, c_{2}^{g}$ and $c_{3}^{g}$ are the correlations of the village specific shocks and $c_{1}^{n}$, $c_{2}^{n}$ and $c_{3}^{n}$ are the correlations of the unobserved idiosyncratic shocks.

Income is often found to be measured with errors in household surveys. This measurement error can be dealt with to some extent if it is constant. It may well be reasonable to assume that the measurement error in income is constant over time. The measurement error in income can be caused by the tendency of the surveyed households to underreport their income, the recall bias, etc. In additionally, as the income data in the ERHS are collected by asking about household income from possible sources, such as from farm income, wage income, an incomplete list of income sources in the questionnaire can also cause measurement error in income. As these causes apply to every round of the survey and are likely to affect income in each round in the same proportion, the measurement error in income is a component of $b_{v h}$. Since I have included as many variables which capture the household effect as possible in the independent variables of the income equation, a big part of $b_{v h}$ should be the measurement error and estimating $b_{v h}$ should allow me to deal with the measurement error to some extent. 
Considering that $b_{v h}$ mainly captures the measurement error in income, I can now write the expected income $E_{t-1}\left(y_{v h t} \exp \left(-b_{v h}\right)\right)$ as:

$$
\begin{aligned}
E_{t-1}\left(y_{v h t} \exp \left(-b_{v h}\right)\right)= & \left(\alpha_{1} k_{v h t-1}^{-\rho}+\alpha_{2} l a b_{v h t-1}^{-\rho}+\alpha_{3} l a n_{v h t-1}^{-\rho}\right)^{-\frac{\tau}{\rho}} \exp \left(\sum_{i} \eta_{i} a_{i, v h t-1}\right. \\
& \left.+\sum_{j} \phi_{j} c_{j, v h}+c o n s\right) \times E_{t-1} \exp \left(\sum_{p} \lambda_{p} w_{p, v h t}\right. \\
& \left.+\sum_{q} \chi_{q} o_{q, v h t}+\sum_{t} \varpi_{t} l_{t}+g_{v t}+n_{v h t}\right)
\end{aligned}
$$

Assuming $\sum_{p} \lambda_{p} w_{p, v h t}+\sum_{q} \chi_{q} o_{q, v h t}+\sum_{t} \varpi_{t} l_{t} \sim N\left(0, \sigma_{o}^{2}\right)$, I can rewrite equation (7) as:

$$
\begin{aligned}
E_{t-1}\left(y_{v h t} \exp \left(-b_{v h}\right)\right)= & \left(\alpha_{1} k_{v h t-1}^{-\rho}+\alpha_{2} l a b_{v h t-1}^{-\rho}+\alpha_{3} l a n_{v h t-1}^{-\rho}\right)^{-\frac{\tau}{\rho}} \exp \left(\sum_{i} \eta_{i} a_{i, v h t-1}\right. \\
& \left.+\sum_{j} \phi_{j} c_{j, v h}+\text { cons }+\frac{\sigma_{o}^{2}+\sigma_{g}^{2}+\sigma_{n}^{2}}{2}\right)
\end{aligned}
$$

and the shock can be defined as:

$$
\begin{aligned}
s_{v h t}^{y}= & y_{v h t} \exp \left(-b_{v h}\right)-E_{t-1}\left(y_{v h t} \exp \left(-b_{v h}\right)\right) \\
= & E_{t-1}\left(y_{v h t} \exp \left(-b_{v h}\right)\right)\left(\operatorname { e x p } \left(\sum_{p} \lambda_{p} w_{p, v h t}+\sum_{q} \chi_{q} o_{q, v h t}+\sum_{t} \varpi_{t} l_{t}\right.\right. \\
& \left.\left.+g_{v h}+n_{v h t}-\frac{\sigma_{o}^{2}+\sigma_{g}^{2}+\sigma_{n}^{2}}{2}\right)-1\right) \\
= & E_{t-1}\left(y_{v h t} \exp \left(-b_{v h}\right)\right)\left(\exp \left(d_{v h t}^{y}\right)-1\right)
\end{aligned}
$$

where $d_{v h t}^{y}=\sum_{p} \lambda_{p} w_{p, v h t}+\sum_{q} \chi_{q} o_{q, v h t}+\sum_{t} \varpi_{t} l_{t}+g_{v h}+n_{v h t}-\frac{\sigma_{o}^{2}+\sigma_{g}^{2}+\sigma_{n}^{2}}{2}$. 
I use Feasible Generalized Least Squares to estimate this model. The details of the estimation procedure can be found in Appendix A. Table 5 shows the estimation results of the income function.

From estimating the income function, I obtain the residual from the estimation which is an estimate of $e_{v h t}$ (denoted by $\widehat{e_{v h t}}$ ). I regress $\widehat{e_{v h t}}$ on the village dummies to get an estimate of $g_{v t}$ (denoted by $\widehat{g_{v t}}$ ).

To obtain an estimate of $b_{v h}$, I regress $\widehat{e_{v h t}}-\widehat{g_{v t}}$ on the household dummies. This allows me to obtain an estimate of $b_{v h}+\overline{n_{v h t}}$ (denoted by $b_{v h} \widehat{+\bar{n}_{v h t}}$ ). Since the panel is short, it is not reasonable to assume that $\overline{n_{v h t}}$ is equal to zero. Thus it is necessary to exclude it from $b_{v h} \widehat{+\bar{n}_{v h t}}$ in order to obtain an estimate of $b_{v h}$. I achieve this by regressing $b_{v h} \widehat{+\bar{n}_{v h t}}$ on the the change of the crops households stored from the first round to the fourth round.

This is based on the understanding that households store crops when there is a good harvest and consume or sell them when there is a bad harvest. Therefore, if the average shock is positive (negative) in the period from year 94 to year 97, the crops households stored should increase (decrease) in this period. This relation can be written as:

$$
\overline{\sum_{p} \lambda_{p} w_{p, v h t}+\sum_{q} \chi_{q} o_{q, v h t}+\sum_{t} \varpi_{t} l_{t}+g_{v t}+n_{v h t}}=f\left(c r_{v h 97}-c r_{v h 94}\right)+e r
$$

where $c r_{v h 94}$ and $c r_{v h 97}$ are the crops the household stored in the first and the fourth round respectively, er is the error term and $f(\cdot)$ is a functional form ${ }^{12}$. 
Since the variable 'crop storage' can be measured without many difficulties in household surveys, it is unlikely that it is correlated with the measurement error in income. Therefore, if I regress

$$
b_{v h} \widehat{+\bar{n}_{v h t}}+\overline{\sum_{p} \widehat{\lambda}_{p} w_{p, v h t}+\sum_{q} \widehat{\chi}_{q} o_{q, v h t}+\sum_{t} \widehat{\varpi}_{t} l_{t}+\widehat{g}_{v t}}
$$

on $f\left(c r_{v h 97}-c r_{v h 94}\right)$, the residual from this regression can be used as an estimate of $b_{v h}$. The results of this regression is reported in Appendix B.

With the estimates of the coefficients in the income equation and the estimates of $g_{v t}, b_{v h}$ and $n_{v h t}{ }^{13}$, the expected value of income and the shock defined in equation (8) and (9) can be calculated. I then regress $d_{v h t}^{y}$ on village-year dummies to decompose it into the covariant part (denoted by $\left.d_{v h t}^{c o v}\right)$ and the idiosyncratic part (denoted by $d_{v h t}^{i n d}$ ). Then the total income shocks $s_{v h t}^{y}$ can be decomposed into two parts: the covariant income shock $s_{v h t}^{c o v}$ and the idiosyncratic income shock $s_{v h t}^{i d i}$ :

$$
\begin{aligned}
& s_{v h t}^{c o v}=\frac{d_{v h t}^{c o v}}{d_{v h t}^{y}} s_{v h t}^{y}, \\
& s_{v h t}^{i d i}=\frac{d_{v h t}^{i n d}}{d_{v h t}^{y}} s_{v h t}^{y} .
\end{aligned}
$$

\subsection{Transfers, risk pooling and redistribution}

To study the relation between transfers, risk and income, I specify the following equation to model the functions of risk pooling and redistribution of 
transfers:

$$
\begin{aligned}
t r_{v h t}= & \gamma_{1} s_{v h t}^{c o v}+\gamma_{2} s_{v h t}^{i d i}+\theta\left(E_{t-1} y_{v h t}-\bar{E}_{t-1} y_{v t}\right) \\
& +\sum_{i} \kappa_{i} x_{i, v h t-1}+\sum_{i} \xi_{i} z_{i, v h}+\text { cons }+r_{v h t}
\end{aligned}
$$

where $t r$ is the net transfer the household gets. The control variables are denoted by $x_{i}$ and $z_{i}$, in which village dummies are also included. The constant term is denoted by cons. The variable $r$ is the error term. The parameters $\gamma_{i}, \theta, \kappa_{i}, \xi_{i}$ are coefficients.

To study the function of insurance, I put on the right hand side the measures of covariant and idiosyncratic shocks ${ }^{15}: s_{v h t}^{c o v}$ and $s_{v h t}^{i d i}$, which measure the values of gains (losses) from shocks and $\gamma_{1}, \gamma_{2}$ measure the contribution of transfers to risk pooling directly.

To capture the role that transfers may play in transferring from richer households to poorer households, I put on the right hand side the difference between the expected income of the household and the median of the expected income in the village. If transfers do play a pro-poor role, poorer households should receive more transfers than the richer households. Choosing expected income instead of real income here is based on the asset-based view in measuring poverty, since expected income depends only on the household's assets and productivity. The parameter $\theta$ measures the effects of transfers in reallocating income. 


\section{Results}

\subsection{Results on net transfers}

Table 6 shows the estimation results of equation (13). The three columns show the results for net total transfers, net transfers from government/NGOs and net transfers from mutual support respectively. The coefficients $\gamma_{1}$ and $\gamma_{2}$ measure how much covariant shocks and idiosyncratic shocks are insured through transfers respectively and the coefficient $\theta$ measures the income redistribution role. Evidence on the two roles transfers from government/NGOs may play (the insurance role and the redistribution role) can be found in Table 6. The coefficient $\gamma_{1}$ is significant but $\gamma_{2}$ is insignificant in column 2 , which means that covariant shocks are insured by transfers from government/NGOs but idiosyncratic shocks are not insured ${ }^{16}$. There is statistically significant evidence that transfers from government/NGOs go from households with high expected income to the ones with low expected income since $\theta$ is significant in column 2 .

Transfers from friends/relatives are not found to insure neither covariant nor idiosyncratic shocks since both $\gamma_{1}$ and $\gamma_{2}$ are insignificant in column 3. Like the results in column 2 there is evidence that transfers from friends/relatives play a role in redistribution since $\theta$ is significant in column 3 in Table $6^{17}$.

The findings on risk pooling through mutual support are consistent with what the literature has suggested. As stated in Dercon (2005b), the effectiveness of the informal arrangements varies according to the type of shocks. Addi- 
tionally, informal risk-sharing networks can only insure idiosyncratic but not covariant shocks, since the networks are mainly restrained within a certain boundary (e.g. villages). Table 6 shows that households are indeed not able to insure covariant shocks through transfers as $\gamma_{1}$ in column 3 is insignificant. Within the network, evidence on risk-sharing (though not complete risk-sharing) has been found for many countries (e.g. Jalan and Ravallion 1999 for China, Ravallion and Chaudhuri 1997 for India, De Weerdt and Dercon 2006 for Tanzania). However, in these studies the contributions of transfers on risk-sharing cannot be distinguished from the contributions of other risk-sharing institutions. Morduch (1999) suggests that transfers from mutual support only play a minor role in risk-sharing especially where migration is limited. The risk-sharing of idiosyncratic shocks through mutual support is indeed found to be insignificant in these 15 Ethiopian villages in Table 6 .

The results show that transfers from government/NGOs insure covariant shocks (the coefficient $\gamma_{1}$ is significantly negative in column 2) and idiosyncratic shocks are not significantly insured by transfers from government and NGOs $\left(\gamma_{2}\right.$ in column 2 is not significant at $10 \%$ level in Table 6). Different from transfers from mutual support, transfers from government/NGOs have the ability to help the households pool covariant shocks. As just mentioned, households are not able to pool covariant shocks by relying on their social networks. Thus it is even more necessary for the government and NGOs to insure common shocks like drought, flood etc. Transfers from government and NGOs which target the covariant shocks can always play a role as a use- 
ful safety net to guarantee the effectiveness of the risk-sharing arrangement, as the system of informal risk-sharing arrangement is more likely to be down when income is in general low (Coate and Ravallion 1993). There can be two reasons that idiosyncratic shocks are not insured by transfers from government/NGOs. First, insuring idiosyncratic shocks is difficult and costly since idiosyncratic shocks are much more challenging to be detected. Second, in the communities where well-functioning risk-sharing arrangements exist, it is not necessary for the government and NGOs to target idiosyncratic shocks.

\subsection{Results on transfers received}

Since the data only provides information on limited categories of outflows of transfers (taxes and contributions to peasant associations, educational and medical expenses households pay for members of other households, contributions to church and iddir, and contributions for livestock loss), the measures of the outflows of transfers may be incomplete. I redo the regressions shown in Table 6 but instead of net transfers I put the measures of transfers received on the left hand side. Considering there may be differences between income from food-for-work programs and other transfers received from government/NGOs, I do the regressions for them separately. The results are shown in Table 7 . The three columns show the results for transfers received from government/NGOs (excluding income from food-for-work programs), income from food-for-work programs and transfers received from mutual support respectively. 
In terms of insurance, the transfers received from government/NGOs and income from food-for-work programs play a role in insuring covariant shocks ( $\gamma_{1}$ is equal to -0.0015 with a t-value of -3.16 in column 1 and equal to -0.0031 with a t-value of -3.06 in column 2 ). Transfers received from mutual support do not contribute to insuring income shocks as both $\gamma_{1}$ and $\gamma_{2}$ are highly insignificant in column 3. These findings are consistent with the results in Table 6 .

In column $2, \gamma_{2}$ is significantly positive (the value is very close to zero though). This means that households with negative idiosyncratic income shocks receive less from food-for-work programs. One explanation is that when there are food-for-work programs set up at a location suffering from covariant shocks, households suffering higher idiosyncratic shocks face more constraints to join the programs. For example, if one or more members of a household are having health problems, the household may find that it does not have extra labor to join the programs. There is no evidence in Table 7 that transfers received contribute to income redistribution ${ }^{18}$.

\subsection{Results on consumption}

The measured shocks described in this paper can be easily used to study how much risk is insured in total. Transfers play only a small role in risk pooling in these 15 Ethiopian villages. If getting transfers is the only strategy households use to stabilize their consumption, their consumption should 
move almost perfectly along with the shocks. However, this is not the case. I redo the regression shown in equation (13) but put household yearly consumption on the left hand side instead. The results are shown in Table 8. Consumption does move along with shocks since both $\gamma_{1}$ and $\gamma_{2}$ are positive. However, both coefficients significantly differ from 1. The coefficient of the covariant shock is equal to 0.500 which means that households can only insure about half of the covariant shocks. The idiosyncratic shocks are however well insured. Only $9 \%$ of the variation in idiosyncratic shocks leads to variation in consumption.

\section{Conclusion}

This paper studies the role of transfers in risk pooling and redistribution in Ethiopia. It explores how much risk pooling is achieved through transfers for households in ERHS villages using a regression based concept of income shocks. From a regression of net transfers on income shocks, the covariant shocks are found to be partially insured by transfers from government/NGOs. However, the impact is very limited. Transfers from mutual support do not

play a role in risk pooling. There is also evidence that transfers play a role in redistributing income from richer to poorer households.

The results indicate that the aid provided through food aid and food-forwork programs do not generate much help to the ones who actually need it. Only the covariant shocks faced by the households are found to be insured 
by these transfers at a very low level. Both transfers received from food-forwork programs and other transfers from government/NGOs do not seem to have a significant impact on income redistribution.

The results also provide insights in the scope for introducing formal insurance to insure shocks. Results here have shown that transfers from informal social networks do not play a role in risk pooling. Even if "crowding out" does happen when formal insurance is implemented, it will only have a very minor impact on risk pooling.

Since the results on consumption show that households insure part of the covariant shocks and most of the idiosyncratic shocks, though transfers play only a small role in insurance, savings may serve an important role in stabilizing consumption in these 15 Ethiopian villages. Therefore, the impact of savings on risk pooling is an essential question and needs further research. Though most of the research on risk pooling strategies studies the impact of different strategies separately, one should notice that the impact of transfers on risk pooling is not isolated from the impact of other strategies (e.g. savings) in reality. However, evaluating the impact of the strategies jointly cannot be achieved by estimating reduced-form regressions. Further research of evaluating the impact of transfers and savings jointly by employing more sophisticated models will be very helpful in more deeply understanding the behavior of the households. 


\section{Appendix A: Estimating the income function}

I use Feasible Generalized Least Squares (FGLS) to estimate the income function defined in section 3.1.

$$
\begin{aligned}
y_{v h t}= & \left(\alpha_{1} k_{v h t-1}^{-\rho}+\alpha_{2} l a b_{v h t-1}^{-\rho}+\alpha_{3} l a n_{v h t-1}^{-\rho}\right)^{-\frac{\tau}{\rho}} \\
& \exp \left(\sum_{i} \eta_{i} a_{i, v h t-1}+\sum_{j} \phi_{j} c_{j, v h}+\sum_{t} \varpi_{t} l_{t}+\sum_{p} \lambda_{p} w_{p, v h t}\right. \\
& \left.+\sum_{q} \chi_{q} o_{q, v h t}+c o n s+e_{v h t}\right), \\
l a b_{v h t-1}= & m_{v h t-1}+\beta_{1} f_{v h t-1}+\beta_{2} c h_{v h t-1}, \\
e_{v h t}= & g_{v t}+b_{v h}+n_{v h t}, \\
\operatorname{cov}\left(e_{v h, 94}, e_{v h, 95}\right)= & c_{1}^{g} \sigma_{g}^{2}+\sigma_{b}^{2}+c_{1}^{n} \sigma_{n}^{2}=\sigma_{1}^{2}, \\
\operatorname{cov}\left(e_{v h, 95}, e_{v h, 97}\right)= & c_{2}^{g} \sigma_{g}^{2}+\sigma_{b}^{2}+c_{2}^{n} \sigma_{n}^{2}=\sigma_{2}^{2}, \\
\operatorname{cov}\left(e_{v h, 94}, e_{v h, 97}\right)= & c_{3}^{g} \sigma_{g}^{2}+\sigma_{b}^{2}+c_{3}^{n} \sigma_{n}^{2}=\sigma_{3}^{2} .
\end{aligned}
$$

which can be written as:

$$
\begin{aligned}
\log \left(y_{v h t}\right)= & \left(-\frac{\tau}{\rho}\right) \log \left(\alpha_{1} k_{v h t-1}^{-\rho}+\alpha_{2} l a b_{v h t-1}^{-\rho}+\alpha_{3} \operatorname{lan}_{v h t-1}^{-\rho}\right) \\
& +\sum_{i} \eta_{i} a_{i, v h t-1}+\sum_{j} \phi_{j} c_{j, v h}+\sum_{t} \varpi_{t} l_{t}+\sum_{p} \lambda_{p} w_{p, v h t} \\
& +\sum_{q} \chi_{q} o_{q, v h t}+\text { cons }+e_{v h t}, \\
l a b_{v h t-1}= & m_{v h t-1}+\beta_{1} f_{v h t-1}+\beta_{2} c h_{v h t-1} .
\end{aligned}
$$

It is obvious that the parameters of this function will not be estimated efficiently and the estimators of the covariance matrix will not be valid if it is estimated by Nonlinear Least Square (NLS) because the error terms are cor- 
related through $g_{v t}$ and are also serially correlated. I use FGLS to estimate this function. The Generalized Least Squares estimator of this function is

$$
\left.(\log (y)-\widehat{\log (y}))^{T} \Omega^{-1}(\log (y)-\widehat{\log (y})\right)
$$

where $\widehat{\log (y)}$ is the fitted value of $\log (y)$ and $\Omega$ is the variance-covariance matrix of the error term.

The essential part of the estimation is to obtain an estimate of $\Omega$. If two observations are from different villages their error terms are not correlated. If two observations are from the same year and village, the error terms are correlated through $g_{v t}$. The error terms are also serially correlated.

To get estimates of the covariance matrix, estimates of the variances of the three components of the shocks are needed. I do this by first estimating the function using NLS so I can get estimates of $e_{v h t}$ (denoted by $\widehat{e_{v h t}}$ ). After doing a NLS estimation, I perform the following steps:

1. Run a regression of $\widehat{e}_{v h t}$ on the village-year dummies. The fitted values from this regression are taken as the estimates of $g_{v t}\left(\widehat{g_{v t}}\right)$ and the residuals are taken the estimates of $b_{v h}+n_{v h t}\left(b_{v h} \widehat{+n_{v h t}}\right)$.

2. Calculate the variances of $\widehat{g_{v t}}$ and $b_{v h} \widehat{+n_{v h t}}$ to get $\widehat{\sigma_{g}^{2}}$ and $\widehat{\sigma_{b}^{2}+\sigma_{n}^{2}}$ and plug in these variances into the covariance matrix $\Omega$.

3. Calculate the variances of $e_{94}$ and $e_{95}$ as an estimate of $\widehat{\sigma_{1}^{2}}$ and get $\widehat{\sigma_{2}^{2}}$ and $\widehat{\sigma_{3}^{2}}$ in the same way. Plug the variances into the covariance matrix 
$\Omega$.

4. Do the FGLS estimation by using the estimate of $\Omega$.

\section{Appendix B: Results of the regression on crop}

\section{storage}

Dependent variables $\quad b_{v h} \widehat{+\bar{n}_{v h t}}+\overline{\sum_{p} \widehat{\lambda}_{p} w_{p, v h t}+\sum_{q} \widehat{\chi}_{q} o_{q, v h t}+\sum_{t} \widehat{\varpi}_{t} l_{t}+\widehat{g}_{v t}}$

Independent variables Coef. ${ }^{(1)} \quad$ t-statistic

$f\left(c r_{v h 97}-c r_{v h 94}\right) \quad 0.043^{* * *} \quad 3.28$

$\begin{array}{lll}\text { cons } & 1.136^{* * *} & 6.69\end{array}$

obs. 1461

R-squared $\quad 0.007$

(1) $*$ significant at $10 \%$ level; $* *$ significant at $5 \%$ level; $* * *$ significant at $1 \%$ level. 


\section{Notes}

${ }^{1}$ The contingent repayment with the loans makes the loans very similar to transfers in the Udry studies.

${ }^{2}$ This section mainly draws on Dercon and Krishnan (1998).

${ }^{3} \mathrm{~A}$ local government institution covering one or more villages.

${ }^{4}$ During the initial land reform in 1975 and the subsequent redistributions, peasant associations were instructed to use household size as the criterion to allocate land. There are also other factors that determine land allocation. For example, land quality, if the household is newly formed, if the household had cultivated on a certain land etc.

${ }^{5}$ Calculated based on the ERHS data.

${ }^{6}$ Transfers from organizations like the $i d d i r$ funeral association are also included in this category since these transfers are from households' social networks and are part of the mutual support.

${ }^{7}$ To provide more formal evidence of this, I regress the value of transfers on the median of income. I find that the poorer villages received more from both government/NGOs and friends/relatives and the richer villages paid out more to government/NGOs. I am indebted to one of the referees for suggesting these regressions.

${ }^{8}$ This functional form and the choice of most of the variables are based on Cockburn (2002).

${ }^{9}$ This measure of labor is not responsive to shocks. With the setting of this paper, if labor is indeed responsive to shocks, it will be counted as shocks.

${ }^{10}$ Since stratification was used in choosing households to survey, I include indicator variables for landless and female households in $a_{i}$ in order to pool all the data. The information for weighing the sample is limited, as stated in the data description by Dercon and Hoddinott (2004), so no sampling weights are used in the regressions.

${ }^{11}$ Since the panel is short and the income equation is highly nonlinear, estimating the income equation with a household fixed effect does not give sensible estimates of the coefficients.

${ }^{12}$ The form of $f(\cdot)$ used in this paper is $\delta_{1}+\delta_{2} \frac{c r_{v h 97}-c r_{v h 94}}{c r_{v h 97}+c r_{v h 94}+1}$, where $\delta_{1}$ and $\delta_{2}$ are 
coefficients. Dividing by the mean of $c r_{v h 97}$ and $c r_{v h 94}$ makes the expression unit-free and adding one allows to include the observations with no crop stored in both years 94 and 97 .

${ }^{13}$ The estimate of $n_{v h t}$ is the sum of the residual from regressing $\widehat{e_{v h t}}-\widehat{g_{v h}}$ on the household dummies and the estimate $\widehat{n_{v h t}}$.

${ }^{14}$ Decomposed in this way, the shock measures have the following characteristics: 1. $s_{v h t}^{c o v}+s_{v h t}^{i d i}=s_{v h t}^{y} ; 2 . s_{v h t}^{c o v}$ and $d_{v h t}^{c o v}$ have the same sign and $s_{v h t}^{i n d}$ and $d_{v h t}^{\text {ind }}$ have the same sign; 3 . When $s_{v h t}^{y}$ goes to zero, $d_{v h t}^{y}$ also goes to zero.

${ }^{15}$ One may argue that the study can be done by putting the observed shocks directly into equation (13) and there is no need to construct $s_{v h t}^{c o v}$ and $s_{v h t}^{i d i}$. There are two reasons that the method described in this paper is preferred. First, only a subset of the shocks are observed. Second, most of the observed shocks are only qualitative measures of the shocks. The method used in this paper provides a way to measure the shocks quantitatively and integrate all the shocks into two measures. If I do a regression of transfers on the observed shocks, because of the omitted variables in the regression and the collinearity between the variables of the observed shocks, some of the estimates of the coefficients do not seem to be sensible. Moreover, since the observed shocks are only a subset of the shocks, it is hard to evaluate the extent of risk pooling by investigating these coefficients.

${ }^{16}$ One may argue that transfers should have two components: the expected transfers (tr1) and the unexpected transfers (tr2). tr1 might respond to tr2. This makes it desirable to regress $\operatorname{tr} 1$ on the sum of tr2 and the shocks derived in the paper. Unfortunately the data do not allow breaking the transfers into tr1 and tr2. However, suppose this were feasible, then the estimates I report in the paper should be an overestimate of the true impact of transfer on risk pooling (attenuation bias). This reinforces my conclusion that the impact of transfers on risk pooling is very small.

${ }^{17}$ As mentioned in section 2, extreme values of transfers are observed for some of the households. These observations may change the results of the estimation. To detect outliers, I use two criteria: 1. Studentized residuals, Cook's distance, leverage, DFITS or DFBETA of $s_{v h t}^{c o v}, s_{v h t}^{i d i}, E_{t-1} y_{v h t}-\bar{E}_{t-1} y$ exceed their cutoffs. 2. Household income is in the highest or lowest percentiles, or livestock the household owns is in the highest percentile, or land the household owns is in the highest percentile, or total transfers of 
the household is in the highest or lowest percentiles. If both criteria are satisfied, the observation is considered to be an outlier and is deleted from the analysis. In total 91 out of 4164 observations are dropped. Including the outliers in the sample, I found that all the estimates of $\gamma_{1}, \gamma_{2}$ and $\theta$ are not significant at $10 \%$ level. Only $\gamma_{1}$ for transfers from government/NGOs is significant at $15 \%$ level.

${ }^{18}$ Regressing taxes and contributions to peasant associations on the independent variables in Table 7 (results not shown), I find that these taxes and contributions contribute to income redistribution. This is the reason that transfers from government/NGOs are found to play a role in redistribution in Table 6 . 


\section{References}

Baulch, Bob and John Hoddinott. 2000. Economic Mobility and Poverty Dynamics in Developing Countries, Frank Cass Publishers.

Clay, Daniel C., Daniel Molla and Debebe Habtewold. 1999. "Food aid targeting in Ethiopia: A study of who needs it and who gets it." Food Policy 24: 391-409.

Coate, Stephen and Martin Ravallion. 1993. "Reciprocity without Commitment: Characterization and Performance of Informal Insurance Arrangements." Journal of Development Economics 40: 1-24.

Cockburn, John. 2002. "Income Contributions of Child Work in Rural Ethiopia."

Working Paper Series No. 2002-12, Oxford University, Center for the Study of African Economies.

Deaton, Angus. 1991. "Saving and Liquidity Constraints." Econometrica 59: 1221-1248.

Dercon, Stefan. 1996. "Risk, Crop Choice and Savings: Evidence from Tanzania." Economic Development and Cultural Change 44: 485-513.

—. 2004. "Growth and Shocks: Evidence from Rural Ethiopia." Journal of Development Economics 74: 309-329.

-. 2005a. "Risk, Insurance and Poverty: A Review." In Insurance Against Poverty, ed. Stefan Dercon. Oxford University Press.

-. 2005b. "Risk, Poverty and Public Action." In Insurance against Poverty, ed. Stefan Dercon. Oxford University Press.

Dercon, Stefan and John Hoddinott. 2004. "The Ethiopian Rural Household Surveys: Introduction.” Data description, ERHS. 
Dercon, Stefan, John Hoddinott and Tassew Woldehanna. 2005. "Shocks and Consumption in 15 Ethiopian Villages, 1999-2004." Journal of African Economies 14: 559-585.

Dercon, Stefan and Pramila Krishnan. 1998. "Changes in Poverty in Rural Ethiopia 1989-95: Measurement, Robustness Tests and Decomposition." Discussion Paper Series No. 98.19, Oxford University, Center for the Study of African Economies.

—. 2003. "Food Aid and Informal Insurance." Discussion Paper No. 2003/09, World Institute for Development Economics Research, Helsinki, Finland.

De Weerdt, Joachim and Stefan Dercon. 2006. "Risk-sharing Networks and Insurance against Illness." Journal of Development Economics 81: 337-356. Fafchamps, Marcel. 2003. Rural Poverty, Risk and Development. Edward Elger Publishing Ltd.

Fafchamps, Marcel and Flore Gubert. 2005. "The Formation of Risk Sharing Networks." Working Paper No. DT/2005/13, DIAL, Paris.

Fafchamps, Marcel and Susan Lund. 2003. "Risk-sharing Networks in Rural Philippines." Journal of Development Economics 71: 261-287.

Grimard, Franque. 1997. "Household Consumption Smoothing through Ethnic Ties: Evidence from Cote d'Ivoire." Journal of Development Economics 53: $391-422$.

Hoddinott, John, Stefan Dercon and Pramila Krishnan. 2005. "Networks and Informal Mutual Support in 15 Ethiopian Villages." Working Paper, Oxford University, Center for the Study of African Economies.

Jacoby, Hanan G. and Emmanuel Skoufias. 1997. "Risk, Financial Markets, and Human Capital in a Developing Country." The Review of Economic 
Studies 64: 311-335.

Jalan, Jyotsna and Martin Ravallion. 1999. "Are the Poor Less Well Insured? Evidence on Vulnerability to Income Risk in Rural China." Journal of Development Economics 58: 61-81.

—. 2001. "Behavioral Responses to Risk in Rural China." Journal of Development Economics 66: 23-49.

Kinsey, Bill, Kees Burger and Jan W. Gunning. 1998. "Coping with Drought in Zimbabwe: Survey Evidence on Responses of Rural Households to Risk." World Development 26: 89-110.

Kochar, Anjini. 1999. "Smoothing Consumption by Smoothing Income: Hoursof-Work Responses to Idiosyncratic Agricultural Shocks in Rural India." The Review of Economics and Statistics 81: 50-61.

Lybbert, Travis J., Christopher B. Barrett, Solomon Desta and D. Layne Coppock. 2004. "Stochastic Wealth Dynamics and Risk Management among a Poor Population." The Economic Journal 114: 750-777.

Morduch, Jonathan. (1999). "Between the State and the Market: Can Informal Insurance Patch the Safety Net?" The World Bank Research Observer 14: $187-207$.

Ravallion, Martin and Shubbam Chaudhuri. 1997. "Risk and Insurance in Village India: Comment." Econometrica 65: 171-184.

Rosenzweig, Mark R. 1988. "Risk, Implicit Contracts and Family in Rural Areas of Low-Income countries." The Economic Journal 98: 1148-1470.

Townsend, Robert M. 1994. "Risk and Insurance in Village India." Econometrica 62: 539-591.

Udry, Christopher. 1990. "Credit Markets in Northern Nigeria: Credit as 
Insurance in a Rural Economy." World Bank Economic Review 4: 251-269. —. 1994. "Risk and Insurance in a Rural Credit Market: An Empirical Investigation in Northern Nigeria." The Review of Economic Studies 61: 495-526. 
yearly income $(y) \quad$ Household income excluding transfers (in Birr $\left.{ }^{(2)}\right)$

male $(m)$

Male household members (age $\geq 16$ )

female $(f) \quad$ Female household members (age $\geq 16$ )

child $(\mathrm{ch}) \quad$ Household members aged between 6 and 15

livestock $(k) \quad$ Value of the livestock owned by the household (in Birr) divided by 1000

$2933.32 \quad 13585.41$

land (lan)

Land owned by the household (in hectares)

other assets Value of other productive assets (hoes, plows, etc.) owned by household (in Birr)

Dummy:=1 if the household has no land; 0 if not

Share of land which is lem (good land)

em

Dummy:=1 if the household has (a) coffee plant(s); 0 if not

$\begin{array}{ll}\text { coffee } & \text { Dummy }:=1 \text { if the household has (a) chat plant(s); } 0 \text { if not }\end{array}$

enset

Dummy:=1 if the household has (a) enset plant(s); 0 if not

eucalyptus

Dummy:=1 if the household has (a) eucalyptus plant(s); 0 if not

fel_head

Dummy:=1 if the household head is female; 0 if not

Age of the household head

education $\quad$ Years of education of the household head

haresaw Dummy:=1 if the household in Haresaw site; 0 if not

Dummy: $=1$ if the household in Geblen site; 0 if not

Dummy: $=1$ if the household in Dinki site; 0 if not

Dummy:=1 if the household in Debre Berhan site; 0 if not

Dummy: $=1$ if the household in Yetmen site; 0 if not

Dummy:=1 if the household in Shumsha site; 0 if not

Dummy: $=1$ if the household in Sirbana Godeti site; 0 if not

Dummy: $=1$ if the household in Adele Keke site; 0 if not

Dummy:=1 if the household in Koro-degaga site; 0 if not

Dummy:=1 if the household in Turfe Kechemane site; 0 if not

Dummy:=1 if the household in Imdibir site; 0 if not

Dummy:=1 if the household in Aze Deboa site; 0 if not

Dummy: $=1$ if the household in Addado site; 0 if not

Dummy: $=1$ if the household in Gara Godo site; 0 if not

$\begin{array}{ll}1.54 & 0.94 \\ 1.81 & 1.53\end{array}$

$2.06-3.16$

$2.49 \quad 38.81$

$52.65 \quad 148.73$

$\begin{array}{rr}0.65 & 148.73 \\ 0.09 & 0.29\end{array}$

$0.42 \quad 0.43$

$0.27 \quad 0.44$

$0.29 \quad 0.45$

$\begin{array}{ll}0.29 & 0.45 \\ 0.34 & 0.47\end{array}$

$\begin{array}{ll}0.34 & 0.47 \\ 0.21 & 0.41\end{array}$

$46.40 \quad 16.42$

$1.52 \quad 2.74$

$0.05-0.22$

$0.04-0.20$

$\begin{array}{ll}0.06 & 0.23 \\ 0.13 & 0.33\end{array}$

$\begin{array}{ll}0.04 & 0.33 \\ 0.09 & 0.29\end{array}$

$0.09 \quad 0.29$

sirbana

korod

imdibir

azedeboa

0.07

0.07

(1) Calculated based on the ERHS data.

(2) 1 Birr $\approx 0.1$ USD

(3) Observations with missing values are not included.

Table 1: Definitions and descriptive statistics of the variables 


\begin{tabular}{|c|c|c|c|c|c|c|}
\hline Variable $^{(1)}$ & Obs. ${ }^{(2)}$ & Mean & Median & S.D. & 99th percentile & Max \\
\hline Total transfers in & 1062 & 136 & 57 & 500 & 1300 & 14319 \\
\hline Transfers in from government/NGOs & 445 & 112 & 47 & 687 & 492 & 14319 \\
\hline Food for work & 242 & 120 & 76 & 128 & 603 & 955 \\
\hline Transfers in from friends/relatives & 438 & 150 & 48 & 343 & 1969 & 3518 \\
\hline Total transfers out ${ }^{(3)}$ & 3474 & 39 & 22 & 68 & 272 & 1499 \\
\hline Transfers out to government/NGOs & 2075 & 28 & 19 & 59 & 187 & 1396 \\
\hline Transfers out to friends/relatives & 3136 & 24 & 11 & 47 & 187 & 1081 \\
\hline Food given out & 224 & 584 & 331 & 707 & 3494 & 4387 \\
\hline
\end{tabular}

(1) All the statistics are based on the amount of transfers for four months, the unit is Birr.

(2) All the statistics are calculated only based on nonzero observations.

(3) Excluding food given out.

Table 2: Descriptive statistics of the transfers 


\begin{tabular}{|c|c|c|c|c|c|c|c|c|c|c|c|c|}
\hline \multirow{3}{*}{$\begin{array}{l}\text { Village } \\
\text { Haresaw }\end{array}$} & \multirow{3}{*}{$\begin{array}{c}\text { Year } \\
94\end{array}$} & \multirow{3}{*}{$\begin{array}{c}\text { Medians } \\
\text { of income } \\
1096\end{array}$} & \multicolumn{6}{|c|}{ Government/NGOs ${ }^{(1)}$} & \multicolumn{4}{|c|}{ Friends/Relatives (2) } \\
\hline & & & \multicolumn{2}{|c|}{ Transfers in } & \multicolumn{2}{|c|}{ Food for work } & \multicolumn{2}{|c|}{ Transfers out } & \multicolumn{2}{|c|}{ Transfers in } & \multicolumn{2}{|c|}{ Transfers out } \\
\hline & & & $0^{(3)}$ & $(0 \%)^{(4)}$ & 6121 & $(62 \%)$ & 59 & $(24 \%)$ & 189 & $(4 \%)$ & 162 & $(38 \%)$ \\
\hline & 95 & 460 & 262 & $(5 \%)$ & 2455 & $(23 \%)$ & 443 & $(25 \%)$ & 379 & $(1 \%)$ & 116 & $(25 \%)$ \\
\hline & 97 & 1169 & 94 & $(3 \%)$ & 2590 & $(15 \%)$ & 763 & $(57 \%)$ & 747 & $(12 \%)$ & 605 & $(72 \%)$ \\
\hline \multirow[t]{3}{*}{ Geblen } & 94 & 529 & 141 & $(2 \%)$ & 5790 & $(78 \%)$ & 17 & $(2 \%)$ & 0 & $(0 \%)$ & 70 & $(13 \%)$ \\
\hline & 95 & 334 & 80 & $(2 \%)$ & 42 & $(2 \%)$ & 0 & $(0 \%)$ & 0 & $(0 \%)$ & 0 & $(0 \%)$ \\
\hline & 97 & 135 & 2716 & $(63 \%)$ & 255 & $(5 \%)$ & 328 & $(34 \%)$ & 129 & $(2 \%)$ & 80 & $(27 \%)$ \\
\hline \multirow[t]{3}{*}{ Dinki } & 94 & 577 & 0 & $(0 \%)$ & 0 & $(0 \%)$ & 829 & $(49 \%)$ & 258 & $(1 \%)$ & 276 & $(32 \%)$ \\
\hline & 95 & 155 & 0 & $(0 \%)$ & 0 & $(0 \%)$ & 395 & $(32 \%)$ & 49 & $(3 \%)$ & 139 & $(20 \%)$ \\
\hline & 97 & 967 & 0 & $(0 \%)$ & 0 & $(0 \%)$ & 82 & $(5 \%)$ & 555 & $(4 \%)$ & 247 & $(47 \%)$ \\
\hline \multirow[t]{3}{*}{ Debre Berhan } & 94 & 3054 & 258 & $(1 \%)$ & 0 & $(0 \%)$ & 2392 & $(69 \%)$ & 1067 & $(7 \%)$ & 1527 & $(78 \%)$ \\
\hline & 95 & 1597 & 361 & $(2 \%)$ & 0 & $(0 \%)$ & 1775 & $(88 \%)$ & 5 & $(1 \%)$ & 1263 & $(88 \%)$ \\
\hline & 97 & 2878 & 0 & $(0 \%)$ & 0 & $(0 \%)$ & 838 & $(19 \%)$ & 755 & $(6 \%)$ & 2495 & $(94 \%)$ \\
\hline \multirow[t]{3}{*}{ Yetmen } & 94 & 1588 & 0 & $(0 \%)$ & 0 & $(0 \%)$ & 1181 & $(89 \%)$ & 0 & $(0 \%)$ & 1171 & $(60 \%)$ \\
\hline & 95 & 2159 & 0 & $(0 \%)$ & 0 & $(0 \%)$ & 539 & $(89 \%)$ & 55 & $(5 \%)$ & 254 & $(74 \%)$ \\
\hline & 97 & 3460 & 0 & $(0 \%)$ & 13 & $(2 \%)$ & 274 & $(22 \%)$ & 205 & $(5 \%)$ & 659 & $(65 \%)$ \\
\hline \multirow[t]{3}{*}{ Shumsha } & 94 & 689 & 30626 & $(96 \%)$ & 0 & $(0 \%)$ & 2433 & $(81 \%)$ & 795 & $(3 \%)$ & 3512 & $(87 \%)$ \\
\hline & 95 & 784 & 4175 & $(60 \%)$ & 955 & $(1 \%)$ & 999 & $(72 \%)$ & 414 & $(8 \%)$ & 1286 & $(86 \%)$ \\
\hline & 97 & 1049 & 2820 & $(55 \%)$ & 0 & $(0 \%)$ & 185 & $(8 \%)$ & 296 & $(3 \%)$ & 4169 & (90\%) \\
\hline \multirow[t]{3}{*}{ Sirbaba Godeti } & 94 & 3716 & 115 & $(1 \%)$ & 0 & $(0 \%)$ & 2145 & $(87 \%)$ & 56 & $(1 \%)$ & 3284 & $(96 \%)$ \\
\hline & 95 & 3357 & 0 & $(0 \%)$ & 0 & $(0 \%)$ & 1169 & $(81 \%)$ & 437 & $(4 \%)$ & 2242 & (96\%) \\
\hline & 97 & 3646 & 202 & $(1 \%)$ & 0 & $(0 \%)$ & 5062 & $(73 \%)$ & 461 & $(3 \%)$ & 7083 & $(100 \%)$ \\
\hline \multirow[t]{3}{*}{ Adele Keke } & 94 & 1689 & 0 & $(0 \%)$ & 3151 & $(21 \%)$ & 4347 & $(71 \%)$ & 1699 & $(8 \%)$ & 1722 & $(34 \%)$ \\
\hline & 95 & 2262 & 0 & $(0 \%)$ & 380 & $(1 \%)$ & 300 & $(19 \%)$ & 1023 & $(18 \%)$ & 322 & $(35 \%)$ \\
\hline & 97 & 2766 & 3146 & $(59 \%)$ & 168 & $(1 \%)$ & 12158 & $(78 \%)$ & 695 & $(6 \%)$ & 2240 & $(70 \%)$ \\
\hline \multirow[t]{3}{*}{ Koro-degaga } & 94 & 1053 & 69 & $(1 \%)$ & 0 & $(0 \%)$ & 2213 & $(94 \%)$ & 3979 & $(28 \%)$ & 1408 & $(89 \%)$ \\
\hline & 95 & 1970 & 516 & $(17 \%)$ & 0 & $(0 \%)$ & 1344 & $(82 \%)$ & 6427 & $(28 \%)$ & 1583 & $(92 \%)$ \\
\hline & 97 & 2626 & 506 & $(3 \%)$ & 0 & $(0 \%)$ & 2323 & $(40 \%)$ & 9540 & $(20 \%)$ & 1789 & $(89 \%)$ \\
\hline \multirow[t]{3}{*}{ Turfe Kechemane } & 94 & 2508 & 587 & $(3 \%)$ & 0 & $(0 \%)$ & 138 & $(16 \%)$ & 7842 & $(19 \%)$ & 1837 & $(93 \%)$ \\
\hline & 95 & 3787 & 1413 & $(1 \%)$ & 642 & $(12 \%)$ & 1224 & $(90 \%)$ & 3931 & $(19 \%)$ & 2476 & $(91 \%)$ \\
\hline & 97 & 3862 & 0 & $(0 \%)$ & 0 & $(0 \%)$ & 8 & $(1 \%)$ & 2964 & $(10 \%)$ & 2891 & (96\%) \\
\hline Imdibir & 94 & 4354 & 75 & $(1 \%)$ & 613 & $(6 \%)$ & 59 & $(3 \%)$ & 2990 & $(10 \%)$ & 3742 & (99\%) \\
\hline & 95 & 1431 & 86 & $(13 \%)$ & 2708 & $(51 \%)$ & 592 & $(52 \%)$ & 2616 & $(31 \%)$ & 1004 & $(97 \%)$ \\
\hline & 97 & 1524 & 160 & $(18 \%)$ & 0 & $(0 \%)$ & 901 & $(47 \%)$ & 3962 & $(40 \%)$ & 2175 & $(98 \%)$ \\
\hline Aze Deboa & 94 & 1287 & 0 & $(0 \%)$ & 0 & $(0 \%)$ & 183 & $(5 \%)$ & 1081 & $(14 \%)$ & 6481 & $(90 \%)$ \\
\hline & 95 & 1751 & 68 & $(3 \%)$ & 0 & $(0 \%)$ & 2218 & $(69 \%)$ & 363 & $(13 \%)$ & 1527 & $(100 \%)$ \\
\hline & 97 & 2155 & 414 & $(1 \%)$ & 0 & $(0 \%)$ & 139 & $(4 \%)$ & 3065 & $(19 \%)$ & 1177 & $(97 \%)$ \\
\hline Addado & 94 & 1308 & 22 & $(1 \%)$ & 0 & $(0 \%)$ & 1832 & $(63 \%)$ & 55 & $(1 \%)$ & 2961 & $(76 \%)$ \\
\hline & 95 & 2003 & 0 & $(0 \%)$ & 0 & $(0 \%)$ & 1720 & $(55 \%)$ & 2459 & $(2 \%)$ & 1390 & $(71 \%)$ \\
\hline & 97 & 3082 & 0 & $(0 \%)$ & 0 & $(0 \%)$ & 1211 & $(38 \%)$ & 130 & $(5 \%)$ & 3188 & $(95 \%)$ \\
\hline Gara Godo & 94 & 592 & 0 & $(0 \%)$ & 49 & $(1 \%)$ & 1314 & $(71 \%)$ & 1068 & $(13 \%)$ & 2920 & $(93 \%)$ \\
\hline & 95 & 934 & 0 & $(0 \%)$ & 266 & $(12 \%)$ & 922 & $(74 \%)$ & 47 & $(4 \%)$ & 620 & $(84 \%)$ \\
\hline & 97 & 1199 & 623 & $(7 \%)$ & 82 & $(1 \%)$ & 22 & $(3 \%)$ & 2761 & $(96 \%)$ & 653 & $(97 \%)$ \\
\hline Doma & 94 & 859 & 34 & $(1 \%)$ & 0 & $(0 \%)$ & 958 & $(74 \%)$ & 75 & $(1 \%)$ & 353 & $(56 \%)$ \\
\hline & 95 & 456 & 83 & $(4 \%)$ & 2856 & $(73 \%)$ & 322 & $(34 \%)$ & 16 & $(3 \%)$ & 154 & $(34 \%)$ \\
\hline & 97 & 1036 & 70 & $(2 \%)$ & 0 & $(0 \%)$ & 226 & $(16 \%)$ & 0 & $(0 \%)$ & 538 & $(50 \%)$ \\
\hline
\end{tabular}

Table 3: Value of transfers and percentage of households which received and handed out transfers 


\section{Variable Definition}

Dummy:=1 if the household reported that the rain came on time in the previous farming season; 0 if not Dummy:=1 if the household reported that there was enough rain in the previous farming season; 0 if not Dummy:=1 if the household reported that the rain stopped on time in the previous farming season; 0 if not

Dummy:=1 if the household reported that there was enough rain in the harvest in the previous farming Dummy: $=1$ if
season; 0 if not

$w_{5}$ Dummy:=1 if the household reported that crops suffered from low_temperature in the previous farming season; 0 if not

Dummy:=1 if the household reported that crops suffered from wind/storm in the previous farming season; 0 if not

Dummy:=1 if the household reported that crops suffered from flooding/water logging in the previous farming season; 0 if not

mo household reported that crops suffered from diseases in the previous farming season; 0 if not

$o_{2}$ Dummy:=1 if the household reported that crops suffered from livestock eating/trampling in the previous farming season; 0 if not

$o_{3} \quad$ Dummy: $=1$ if the household reported that crops suffered from birds/other animals in the previous farming season; 0 if not

o4 Dummy: $=1$ if the household reported that crops suffered from weed damage in the previous farming season; 0 if not

O5 The size of land which was allocated to the three crops which were reported by households to be most affected by weather, insects, diseases etc. weighted by the severity of the affection

$o_{6} \quad$ livestock shock: $\frac{b_{v h t}-d_{v h t}}{k_{v h, t-1}}$, where $b_{v h t}$ is the birth of livestock in value and $d_{v h t}$ is the death of livestock in value

$o_{7} \frac{d h_{v h t}}{h_{h s i z e_{v h, t-1}}}$, where $d h_{v h t}$ is the number of household member who died and $h h s i z e_{v h, t-1}$ is the size of household in the beginning of the year

o8 $\frac{\text { join }_{v h t}}{\text { hsize }_{v h, t-1}}$, where join jht $_{\text {is }}$ is the number of household member who joined the household and hhsize $e_{v, t-1}$ is the size of household in the beginning of the year

Table 4: Definitions of variables of observed shocks 


\begin{tabular}{|c|c|c|}
\hline Dependent variable: & & \\
\hline Variable & Coef. ${ }^{(1)}$ & t-statistic \\
\hline scale returns $(\tau)$ & $0.642^{* * *}$ & 16.31 \\
\hline substitution $(\rho)$ & $-0.485^{* * *}$ & -6.71 \\
\hline livestock $\left(\alpha_{1}\right)$ & $0.269^{* * *}$ & 7.42 \\
\hline labor $\left(\alpha_{2}\right)$ & $0.448^{* * *}$ & 9.87 \\
\hline land $\left(\alpha_{3}^{(2)}\right)$ & $0.283^{* * *}$ & 6.86 \\
\hline female $\left(\beta_{1}\right)$ & $0.410^{* * *}$ & 3.91 \\
\hline $\operatorname{kid}\left(\beta_{2}\right)$ & $0.281^{* * *}$ & 3.84 \\
\hline landless & $0.263^{* * *}$ & 2.62 \\
\hline lem & $0.099^{* *}$ & 2.45 \\
\hline coffee & $0.406^{* * *}$ & 5.72 \\
\hline chat & $0.338^{* * *}$ & 4.68 \\
\hline enset & -0.050 & -0.66 \\
\hline eucalyptus & $0.091^{* *}$ & 2.31 \\
\hline fel_head & $-0.130^{* * *}$ & -2.69 \\
\hline age & $-0.005^{* * *}$ & -4.16 \\
\hline education & $0.031^{* * *}$ & 4.61 \\
\hline haresaw & $-0.484^{* *}$ & -2.10 \\
\hline geblen & $-1.267^{* * *}$ & -5.39 \\
\hline dinki & $-1.002^{* * *}$ & -4.35 \\
\hline yetmen & -0.009 & -0.04 \\
\hline shumsha & $-0.502^{* *}$ & -2.23 \\
\hline sirbana & $0.532^{* *}$ & 2.35 \\
\hline adele & 0.174 & 0.74 \\
\hline korod & -0.091 & -0.40 \\
\hline turfe & $0.468^{* *}$ & 2.01 \\
\hline imdibir & -0.099 & -0.38 \\
\hline azedeboa & -0.385 & -1.55 \\
\hline addado & 0.328 & 1.31 \\
\hline garagodo & $-0.726^{* * *}$ & -2.99 \\
\hline doma & $-0.667^{* * *}$ & -2.86 \\
\hline year95 & -0.059 & -0.58 \\
\hline year97 & $0.316^{* * *}$ & 3.09 \\
\hline cons. & $6.902^{* * *}$ & -36.32 \\
\hline observed shocks & not reported & \\
\hline obs. & 4164 & \\
\hline R-squared & 0.45 & \\
\hline
\end{tabular}

Table 5: Estimation results of the income function 


\begin{tabular}{|c|c|c|c|}
\hline Dependent variables: & $\begin{array}{l}\text { Net total } \\
\text { transfers }\end{array}$ & $\begin{array}{l}\text { Net transfers from } \\
\text { government/NGOs }\end{array}$ & $\begin{array}{l}\text { Net transfers from } \\
\text { mutual support }\end{array}$ \\
\hline \multicolumn{4}{|l|}{ Independent variables } \\
\hline$s_{v h t}^{c o v}\left(\gamma_{1}\right)$ & $\begin{array}{c}-0.0056^{* * *(1)} \\
(-3.14)^{(2)}\end{array}$ & $\begin{array}{c}-0.0045^{* * *} \\
(-3.56)\end{array}$ & $\begin{array}{c}-0.0011 \\
(-0.86)\end{array}$ \\
\hline$s_{v h t}^{i d i}\left(\gamma_{2}\right)$ & $\begin{array}{c}0.0002 \\
(0.30)\end{array}$ & $\begin{array}{c}0.0005 \\
(1.06)\end{array}$ & $\begin{array}{c}-0.0003 \\
(-0.66)\end{array}$ \\
\hline$E_{t-1} y_{v h t}-{\overline{E_{t-1}}}_{v t}(\theta)$ & $\begin{array}{c}-0.0070^{* * *} \\
(-5.41)\end{array}$ & $\begin{array}{c}-0.0030^{* * *} \\
(-3.90)\end{array}$ & $\begin{array}{c}-0.0040^{* * *} \\
(-4.18)\end{array}$ \\
\hline landless & $\begin{array}{l}1.024 \\
(0.29)\end{array}$ & $\begin{array}{c}-1.296 \\
(-0.55)\end{array}$ & $\begin{array}{l}2.320 \\
(0.94)\end{array}$ \\
\hline lem & $\begin{array}{c}0.471 \\
(0.17)\end{array}$ & $\begin{array}{l}-1.955 \\
(-0.97)\end{array}$ & $\begin{array}{l}2.426 \\
(1.23)\end{array}$ \\
\hline coffee & $\begin{array}{l}-3.755 \\
(-0.86)\end{array}$ & $\begin{array}{l}-2.274 \\
(-0.98)\end{array}$ & $\frac{-1.481}{(-0.41)}$ \\
\hline chat & $\begin{array}{l}-5.076 \\
(-0.92)\end{array}$ & $\begin{array}{c}-6.810^{* *} \\
(-2.15)\end{array}$ & $\begin{array}{l}1.734 \\
(0.39)\end{array}$ \\
\hline enset & $\begin{array}{l}-3.897 \\
(-0.80)\end{array}$ & $\begin{array}{l}1.457 \\
(0.83)\end{array}$ & $\begin{array}{c}-5.354 \\
(-1.23)\end{array}$ \\
\hline eucalyptus & $\begin{array}{l}-4.890 \\
(-1.63)\end{array}$ & $\begin{array}{l}-1.840 \\
(-0.84)\end{array}$ & $\begin{array}{l}-3.050 \\
(-1.60)\end{array}$ \\
\hline fel_head & $\begin{array}{l}2.666 \\
(0.91)\end{array}$ & $\begin{array}{l}-2.584 \\
(-1.22)\end{array}$ & $\begin{array}{l}5.250^{* * *} \\
(2.59)\end{array}$ \\
\hline age & $\begin{array}{c}0.187^{* * *} \\
(2.69)\end{array}$ & $\begin{array}{c}0.104^{* *} \\
(2.36)\end{array}$ & $\begin{array}{c}0.083 \\
(1.54)\end{array}$ \\
\hline education & $\begin{array}{c}0.553 \\
(1.28)\end{array}$ & $\begin{array}{c}0.489^{* *} \\
(2.16)\end{array}$ & $\begin{array}{c}0.063 \\
(0.18)\end{array}$ \\
\hline cons & $\begin{array}{l}-22.544^{* * *} \\
(-4.94)\end{array}$ & $\begin{array}{l}-11.904^{* * *} \\
(-4.16)\end{array}$ & $\begin{array}{l}-10.640^{* * *} \\
(-3.05)\end{array}$ \\
\hline village dummies & not reported & & \\
\hline obs. & 4080 & 4080 & 4080 \\
\hline R-squared & 0.16 & 0.20 & 0.08 \\
\hline
\end{tabular}

Table 6: Results of net transfers 


\begin{tabular}{|c|c|c|c|}
\hline Dependent variables: & $\begin{array}{c}\text { Transfers received } \\
\text { from government } \\
\text { and NGOs }\end{array}$ & $\begin{array}{l}\text { Income from } \\
\text { food-for-work } \\
\text { programs }\end{array}$ & $\begin{array}{l}\text { Transfers receivec } \\
\text { from mutual } \\
\text { support }\end{array}$ \\
\hline $\begin{array}{l}\text { Independent variables } \\
s_{v h t}^{\text {cov }}\left(\gamma_{1}\right)\end{array}$ & $\begin{array}{c}-0.0015^{* * *(1)} \\
(-3.16)^{(2)}\end{array}$ & $\begin{array}{c}-0.0031^{* * *} \\
(-3.06)\end{array}$ & $\underset{(0.93)}{0.0010}$ \\
\hline$s_{v h t}^{i d i}\left(\gamma_{2}\right)$ & $\begin{array}{c}0.0001 \\
(0.48)\end{array}$ & $\begin{array}{c}0.0005^{*} \\
(1.76)\end{array}$ & $\begin{array}{c}-0.000001 \\
(0.00)\end{array}$ \\
\hline$E_{t-1} y_{v h t}-\bar{E}_{t-1} y_{v t}(\theta)$ & $\begin{array}{c}-0.0004 \\
(-0.89)\end{array}$ & $\begin{array}{c}0.0002 \\
(0.58)\end{array}$ & $\begin{array}{c}-0.0003 \\
(-0.39)\end{array}$ \\
\hline landless & $\begin{array}{c}-2.094 \\
(-1.52)\end{array}$ & $\begin{array}{c}-2.689^{*} \\
(-1.89)\end{array}$ & $\begin{array}{l}2.377 \\
(1.14)\end{array}$ \\
\hline lem & $\begin{array}{c}2.277^{*} \\
(1.64)\end{array}$ & $\begin{array}{c}-1.425 \\
(-1.20)\end{array}$ & $\begin{array}{l}3.367^{* *} \\
(2.06)\end{array}$ \\
\hline coffee & $\begin{array}{l}-2.879 \\
(-1.64)\end{array}$ & $\begin{array}{c}-0.662 \\
(-0.55)\end{array}$ & $\begin{array}{c}-0.328 \\
(-0.11)\end{array}$ \\
\hline chat & $\begin{array}{c}-0.513 \\
(-0.41)\end{array}$ & $\begin{array}{c}-0.638 \\
(-0.24)\end{array}$ & $\begin{array}{l}1.246 \\
(0.35)\end{array}$ \\
\hline enset & $\begin{array}{l}1.798 \\
(1.32)\end{array}$ & $\begin{array}{l}0.075 \\
(0.09)\end{array}$ & $\begin{array}{c}-6.992^{*} \\
(-1.76)\end{array}$ \\
\hline eucalyptus & $\begin{array}{c}0.611 \\
(0.67)\end{array}$ & $\begin{array}{c}-0.232 \\
(-0.14)\end{array}$ & $\begin{array}{c}-2.639^{*} \\
(-1.73)\end{array}$ \\
\hline fel_head & $\frac{-1.816}{(-1.52)}$ & $\begin{array}{l}-2.206 \\
(-1.33)\end{array}$ & $\begin{array}{l}3.592^{*} \\
(1.95)\end{array}$ \\
\hline age & $\begin{array}{c}0.069^{* *} \\
(2.54)\end{array}$ & $\begin{array}{c}0.036 \\
(1.17)\end{array}$ & $\underset{(2.14)}{0.098^{* *}}$ \\
\hline education & $\begin{array}{l}0.332^{* * *} \\
(2.63)\end{array}$ & $\begin{array}{c}-0.075 \\
(-0.54)\end{array}$ & $\begin{array}{l}0.203 \\
(0.81)\end{array}$ \\
\hline cons & $\begin{array}{c}-3.581^{* *} \\
(-1.98)\end{array}$ & $\begin{array}{c}-0.767 \\
(-0.43)\end{array}$ & $\begin{array}{l}-1.842 \\
(-0.67)\end{array}$ \\
\hline village dummies & not reported & & \\
\hline obs. & 4080 & 4080 & 4080 \\
\hline R-squared & 0.24 & 0.14 & 0.05 \\
\hline
\end{tabular}

Table 7: Results of transfers received 


\begin{tabular}{|c|c|}
\hline $\begin{array}{l}\text { Dependent variables } \\
\text { Independent variables }\end{array}$ & Consumption \\
\hline$s_{v h t}^{c o v}\left(\gamma_{1}\right)$ & $\begin{array}{l}0.500^{* * *(1)} \\
\quad(4.71)^{(2)}\end{array}$ \\
\hline$s_{v h t}^{i d i}\left(\gamma_{2}\right)$ & $\begin{array}{c}0.090^{* *} \\
(2.38)\end{array}$ \\
\hline$E_{t-1} y_{v h t}-{\overline{E_{t-1}}}_{v t}(\theta)$ & $\begin{array}{c}1.270^{* * * *} \\
(13.13)\end{array}$ \\
\hline landless & $\begin{array}{c}-69.530 \\
(-0.37)\end{array}$ \\
\hline lem & $\underset{(1.55)}{250.915}$ \\
\hline coffee & $\begin{array}{c}-412.424^{*} \\
(-1.70)\end{array}$ \\
\hline chat & $\begin{array}{l}-583.790^{*} \\
(-1.84)\end{array}$ \\
\hline enset & $\begin{array}{c}-389.133 \\
(-1.47)\end{array}$ \\
\hline eucalyptus & $\begin{array}{c}-73.405 \\
(-0.46)\end{array}$ \\
\hline fel_head & $\begin{array}{c}-481.474^{* * *} \\
(-3.36)\end{array}$ \\
\hline age & $\begin{array}{c}3.998 \\
(1.12)\end{array}$ \\
\hline education & $\begin{array}{c}31.300 \\
(1.05)\end{array}$ \\
\hline cons & $\begin{array}{c}6010.490^{* * *} \\
(19.48)\end{array}$ \\
\hline village dummies & not reported \\
\hline obs. & 4038 \\
\hline R-squared & 0.24 \\
\hline
\end{tabular}

(1) $*$ significant at $10 \%$ level; $* *$ significant at $5 \%$ level; $* * *$ significant at $1 \%$ level.

(2) t-statistics are in the brackets and calculated based on robust standard errors.

Table 8: Results of consumption 